\title{
Exploring usage of mobile banking apps in the UAE: a categorical regression analysis
}

\author{
Sudipa Majumdar ${ }^{1} \cdot$ Vijay Pujari $^{1}$
}

Received: 15 July 2018 / Revised: 26 July 2021 / Accepted: 28 July 2021 / Published online: 9 August 2021

(c) The Author(s), under exclusive licence to Springer Nature Limited 2021

\begin{abstract}
The banking sector has seen major changes with advances in technology. Electronic financial transactions are gradually taking over traditional banking services in terms of transferring funds, utility payments, insurance premium, mortgages and even stock trading. Despite the widespread popularity of smartphones and the advantages of mobile banking, the adoption rates of the mobile apps have been very low all over the world. Our study explored the consumer acceptance of mobile apps in the United Arab Emirates (UAE) by using a structured online questionnaire that was designed using standard variables from the Technology Acceptance Model. Principal component analysis was used to identify and score these factors for the subsequent categorical regression analysis. Consumers were assigned numerical categories depending on their level of usage of the app, and the CATREG nonlinear technique was used to determine the significance of technology acceptance factors. The results show that almost two-thirds of the sample were currently using Mobile Banking apps, and they predominantly belonged to the 30-40 age-group. Perceived usefulness and available information were identified as the main factors influencing acceptance and level of usage of mobile banking apps. This study makes a significant contribution to the existing literature by identifying consumers according to their level of usage and adopting the categorical regression model, which has not been attempted earlier. The results provide important insights for banking professionals in the UAE, in terms of marketing initiatives, information technology and customer service.
\end{abstract}

Keywords Mobile banking · Technology acceptance model · Principal component analysis · Categorical regression · United Arab Emirates

\section{Introduction}

Since the mid-1990s, there has been a fundamental shift in banking delivery platforms in favor of using self-service channels as banking systems have gradually moved toward electronic/internet banking services (Suoranta and Mattila 2004; Laforet and Li 2005; Laukkanen 2007; Sripalawat et al. 2011). Electronic banking could be defined as a portal through which customers access various financial services remotely using devices such as computers, tablets or smartphones (Riquelme and Rios 2010). The phenomenal growth

Sudipa Majumdar

s.majumdar@mdx.ac.ae

Vijay Pujari

V.Pujari@mdx.ac.ae

1 Middlesex University, Knowledge Park, Dubai, UAE in smart mobile phones has created innovative services like payments, banking transactions, portfolio management, etc.

Mobile banking is gradually taking over all traditional banking transactions due to the inherent independence of time/place and the overall convenience. Mobile banking was first introduced in the early 2000s through short messaging services and wireless access protocol (Dasgupta et al. 2011). In their simplest form, mobile banking applications enabled users to receive information on their account balances via text messages. Over the years, banks have sought new strategies to facilitate information sharing and transactions where banking business has been linked through mobile devices to all banking services from anywhere, at any time (Ensor et al. 2012). With the advent of the Wireless Application Protocol and Java-enabled smartphones using General Packet Radio Service (GPRS) support, a wider variety of banking services such as fund transfers between accounts, stock trading and direct utility payments became possible (Pousttchi and Schurig 2004). 
The digital landscape of the United Arab Emirates (UAE) has been transformed in the last decade through conducive infrastructure and policies by the government. UAE has now grown into the most digital-friendly country in the Middle East, with an impressive $99 \%$ of the population being active internet users, according to the UAE Internet and Mobile Statistics (January 2020). The last couple of years have seen an increased focus on digital services in the UAE, with a phenomenal increase in smartphone usage. The massive upswing in the adoption of mobile internet has been attributed to the availability of advanced facilities at low price plans. A majority of users (53\%) in the UAE were found to connect to the internet using smartphones, reaching 18.38 million mobile connections in January 2020.

UAE is striving to become a cashless economy. With the adoption of technological advancements, consumers and businesses follow a contactless payment approach that is considered a convenient, fast and cost-saving mode of transaction. In a bid to promote a cashless society through various smart government initiatives, the Central Bank of UAE supported the launch of Emirates Digital Wallet that is expected to revolutionize the payments landscape drastically. With e-commerce and online transactions on the rise, mobile payment and digital wallet services such as Apple Pay, Google Pay, Samsung Pay have gained consumer confidence making it the payment method of choice. Industry reports projected the mobile wallet to exceed US $\$ 2.3$ billion in 2022 in the UAE (TechSci Research Report 2018). In this scenario, it is imperative to understand the consumer mindset on the usage of mobile banking applications, which would provide valuable foresight and recommendation for the banking sector and Fintech service companies in the UAE.

In this study, we seek to understand mobile banking usage by examining factors that influence customers' intentions to use mobile banking among users in the United Arab Emirates (UAE). The study contributes to the literature since there has been only one study on mobile banking adoption in the UAE (Aboelmaged and Gebba 2013), which focused on a sample of students of a particular educational institution in Dubai. The limitations on the methodology and the sampling techniques used in the previous study have been considered in the present research to increase the explanatory power of the model. More importantly, this study identified the users in terms of the types of transactions they performed through the mobile app. The adoption of mobile banking technology was studied according to the level of usage using the categorical regression model. This is a significant contribution to the existing literature, where the factors affecting the usage have been based on a broad distinction between users and non-users. This study provides important indicators for the providers of mobile banking applications to understand the various antecedents which would help them frame competitive marketing strategies to attract and successfully deliver mobile services. The present research work is focused on determining factors that affect the level of usage of mobile banking applications to provide insightful recommendations to the service providers to gain a competitive advantage in the market.

The paper is structured as follows. The relevant mobile banking literature is reviewed in "Literature review and hypothesis development" section, which also leads to development of the hypotheses to be tested in the research. "Research methodology" section outlines the research methodology, and the results are discussed in "Results" section. Finally, the paper concludes with a summary of results and recommendations.

\section{Literature review and hypothesis development}

There is abundant existing literature on online banking that has explored the adoption and usage of financial activities through bank websites where internet banking has been researched, mainly in terms of the substantial cost savings by banks (Sathye 1999; Robinson 2000; Giglio 2002; Karjaluoto et al. 2003). From the customer point of view, the research in past decades focused mainly on difficulties in adopting a new service (Mols et al. 1999);lack of customer satisfaction without face-to-face interaction (Mattila et al. 2003); security aspects (Sathye 1999; Hamlet and Strube 2000; Howcroft et al. 2002) to name a few. However, there has been a drastic change in the focus of research as online and mobile platforms have proven to be very easy and safe to use, with people quickly adapting to the technological advancements due to the convenience offered.

One of the most utilized models in studying information system acceptance is the technology acceptance model (TAM) (Mathieson 1991; Gefen and Straub 2000; AlGahtani 2001) where the behavior of customers and their adoption are determined by perceived usefulness and perceived ease of use. TAM is based on the Theory of Reasoned Action (TRA) (Fishbein and Ajzen 1975; Ajzen and Fishbein 1980), which is concerned with the determinants of consciously intended behaviors. The development of TRA started in the 1950s, and the model has been used extensively to predict and explain consumer behavior across a wide variety of domains. According to TRA, consumers are rational and would use computers and/or smartphones for their banking services only if they feel that there could be positive benefits associated with using them. Therefore, the underlying premise of TRA is that individuals make decisions rationally and systematically on the basis of the information available to them (Ajzen 1991).

TAM goes a step further and tries to explain usage intentions and acceptance behavior of customers. The usage of 
online or mobile banking requires an understanding of user acceptance in terms of the perceived usefulness and perceived ease of use. In previous studies, these two factors have emerged as crucial in influencing the adoption and indicating the success of mobile banking (Dasgupta et al. 2011; Riquelme and Rios 2010; Koenig-Lewis et al. 2010; Amin et al. 2008; Sripalawat et al. 2011). Davis (1989) defined perceived usefulness as "the degree to which a person believes that using a particular system would enhance his or her job performance". Perceived usefulness affects a person's attitude toward using the system, which implies that e-business applications such as mobile banking would improve performance and efficiency and, in turn, would positively impact the attitude toward the application. Many existing studies have shown that perceived usefulness directly and significantly influences behavioral intention to use a particular technological system (Chen and Ching 2002; Heijden et al. 2003; Guriting and Ndubisi 2006; Khalifa and Shen 2008; Liao et al. 2007; Lin and Chang 2011; Lai and Yang 2009; Luarn and Lin 2005; Nysveen et al. 2005; Wei et al. 2009). Perceived ease of use is "the degree to which a person believes that using a particular system would be free of effort" (Davis 1989). The existing studies suggest that ease of use is a significant attribute of e-business applications since users are concerned with the effort required to use that application and the complexity of the process involved. Perceived ease of browsing, identifying information and performing transactions should, therefore, lead to usage and adoption of the new technology (Chen et al. 2002; Curran and Meuter 2005; Kleijnen et al. 2004; Nysveen et al. 2005; Porter and Donthu 2006; Heijden et al. 2003). Existing research also suggests that ease of use of technology has a direct, positive influence on the expected benefits from the technology (Gefen and Straub 2000; McCloskey 2006; McKechnie et al. 2006; Moon and Kim 2001; Morosan and Jeong 2008). Therefore, we hypothesize:

H1 Perceived ease and usefulness have a positive effect on usage of mobile banking apps.

A broad stream of research has been dedicated to the importance of security and privacy to the acceptance of online and mobile banking (Roboff and Charles 1998; Sathye 1999; Hamlet and Strube 2000; Tan and Teo 2000; Polatoglu and Ekin 2001; Black et al. 2002; Giglio 2002; Howcroft et al. 2002). Many of the studies concluded that privacy and security were significant obstacles to the adoption of online and mobile banking (Sathye 1999; Roboff and Charles 1998; Cranor et al. 1999; Howcroft et al. 2002; Laforet and $\mathrm{Li} 2005$ ) since consumers were unsure of the safety of their transactions and had little confidence in the technology. Consumers were also found unwilling to provide their private information, especially banking details, over the internet (Hoffman and Novak 1998). Hence, perceived risk was a major negative factor affecting the usage of online and mobile banking (Lee et al. 2003; Cruz et al. 2010). Therefore, we hypothesize.

H2 Security and privacy have a positive effect on usage of mobile banking apps.

Another aspect that has a direct impact on the usage and acceptance of technology is the amount of information available to customers about mobile banking. According to Sathye (1999), low awareness would be the factor that would hamper the use of any technology-based service, especially in situations where consumers are unsure or unaware of the possibilities, advantages/disadvantages involved with acceptance of the technology. Suoranta and Mattila (2004) and Laforet and $\mathrm{Li}$ (2005) identified that awareness levels of mobile banking consumers were strongly influenced by the mass media and interpersonal word-of-mouth. Interestingly, Zhou (2011) drew up a causality chain indicating that information quality is the main factor affecting initial trust, which in turn, affects perceived usefulness, and both factors predict the usage intention of mobile banking. Therefore, we hypothesize:

H3 The amount of information a consumer has about mobile banking apps that have a positive effect on their usage.

Quality of internet connection is also another important aspect that emerged from the existing literature (Sathye 1999). Yang (2009) concluded that satisfactory connection and speed of transactions encouraged the use of mobile banking apps. A structural modeling approach was used by Ketkar et al. (2012), who found that consumers considered telecom reach and wireless connectivity as crucial drivers determining the level of usage of mobile banking. Therefore, we hypothesize,

H4 The quality of the Internet connection has a positive effect on the level of usage of mobile banking apps by consumers.

Several other factors that have been studied in the past literature in the context of developed as well as emerging markets. Karjaluoto et al. (2019a, b) studied the case of Finland, a leader in digital banking where self congruence and product novelty were identified as key factors driving perceived value of mobile banking apps, which further led to overall satisfaction and commitment. Consumer intentions to adopt mobile banking services in Pakistan were studied by Glavee-Geo et al. (2017) where gender differences emerged as a significant factor in explaining adoption intentions. Some of the recent studies have looked into various forms of 
remote payments where issues of security and trust emerged as major concerns (Khalilzadeh et al. 2017; Karjaluoto et al. 2019a). Thusi and Maduku studied factors like social influence, hedonic motivation and habit to understand consumer usage of mobile banking apps in South Africa.

\section{Research methodology}

A structured online questionnaire was developed that included questions related to demographic characteristics, the technological background of the respondent, usage of mobile banking and possible factors affecting acceptance of mobile banking in line with the hypotheses outlined above. In order to ensure the content validity of the questionnaire used to assess each of the hypotheses developed, all questions were adapted from previous studies to fit the mobile banking adoption context in the UAE.

The two-part questionnaire captured the demographic and contextual characteristics of the respondents. The first part was used to collect basic information about respondents' gender, age, smart phone experience and usage of mobile banking app. The second part included fivepoint Likert scales, ranging from "strongly disagree" to "strongly agree", used to operationalize the hypotheses that were developed following TAM-based studies, as has been elaborated in the earlier sections. The questionnaire was tested with a focus group consisting of professionals from various industries in the UAE.

Our first step was to analyse interrelationships among all the variables used in our hypotheses and to represent each hypothesis with a smaller number of implicit variables, called 'factors'. Factor analysis is based on a correlation table and is most commonly used to determine the underlying factors responsible for correlations in the data. If there are ' $k$ ' questions, the responses will form the ' $k$ ' independent variables, and factor analysis is used to identify the underlying ' $\mathrm{m}$ ' factors where $m \leq k$, and ' $m$ ' is as small as possible. Principal Component Analysis (PCA) is the predominant extraction method based on factor analysis for reducing dimensionality in a multivariate equation.

The contemporary statistical thought of dimension reduction began with Fisher (1922) which provided the statistical justification for reduction of data by highlighting that "a quantity of data... is to be replaced by relatively few quantities which shall adequately represent... the relevant information contained in the original data". Fisher (1922) laid the foundation for the factor analysis procedures, based on the validation that the number of independent variables is usually greater than the number of facts sought. The inclusion of all the inter-related variables into the regression equation would result in severe problems of multicollinearity. This provides the statistical justification for dimension reduction that needs to be employed where applicable and has been widely adopted in research for parameter estimation. Our study followed the same rigor as we calculated the loadings of each factor by the principal component method. The central idea of the analysis was to reduce the dimensionality of a data set that consists of a large number of inter-related variables by transforming to a new set of uncorrelated variables, using PCA for dimension reduction.

We first conducted the Kaiser-Meyer-Olkin (KMO) Test, which is a measure of suitability of the data for Factor Analysis, by taking partial correlations for each variable in the model and the complete model. The adequacy of sampling is tested through KMO (Kaiser 1970) wherein the test measures sampling adequacy for each variable in the model and for the complete model. The KMO measure of sampling adequacy is given by the formula:

$\mathrm{KMO}_{j}=\sum R_{i j}^{2} / R_{i j}^{2}+\sum U_{i j}^{2}$

where $R_{\mathrm{ij}}$ is the correlation matrix, and $U_{i j}$ is the partial covariance matrix. KMO value varies from 0 to 1 . Factor analysis would be appropriate when variables share common factors, resulting in high values of KMO. Therefore, an average KMO value greater than 0.6 is considered as a good indication for undertaking factor analysis on the dataset (Cerny and Kaiser 1977).

Next, Bartlett's test of sphericity tests whether the observed correlation matrix is significantly different from the identity matrix or not. The test confirms if we can summarize the variables with a fewer number of factors using the null hypothesis that the variables are orthogonal. Bartlett's test, therefore, indicates the acceptable level of partial correlation, thereby justifying that the factors extracted would be meaningful. After conducting factor analysis, a reliability test has to be used to measure the internal consistency of the set of items within a group. The Chronbach Alpha is used for this purpose to calculate the average inter-correlation among the items and if defined as:

$\alpha=k \times c /[v+(k-1) x c]$

where $k$ refers to the number of scale items; $c$ refers to the average of all covariances between items, and $v$ refers to the average variance of each item (Cronbach 1951). When the scale items are independent of one another and share no covariance, then $\alpha=0$ and approaches 1 as the shared covariances become higher. Therefore, the higher the $\alpha$ coefficient, the variables measure a similar underlying concept, such that alpha value of greater than 0.7 is considered acceptable for the factors to be reliable for factor analysis.

The components were determined by the loadings, which calculate how much a factor explained the underlying variable, such that high loadings (positive or negative) 
indicate that the factor strongly influences the variable. The first factor explains the maximum variance and successive components explain progressively smaller portions of the variance and are uncorrelated. Communality shows the proportion of the variance of each variable that is explained by the factors-the closer the communality is to 1 , the better the variable is explained by the factors. In the second step, the loadings were rotated using the varimax rotation method. Varimax is an orthogonal rotation method that minimizes the number of variables that have high loadings on each factor and simplifies the columns of the loading matrix. Finally, factor scores for each respondent were computed, which were then used in the subsequent regression analysis.

The dependent variable used in the regression analysis was the level of usage of mobile banking by the respondents. The usage was based on whether the app was being utilized for bank transfers; making payments; the mobile app was linked to their insurance plans, and/or they were paying for investments like property mortgages, stock markets, other savings-investment solutions through their banking app. Accordingly, the users were categorized as being basic level, moderate level and high level users of the mobile banking app and were assigned numerical categories. Therefore, the "usage" variable was assigned numerical values where the values were corresponding to an ordinal scale, and this was used as an ordinal categorical dependent variable and was used in the categorical regression. The usage was categorized as follows:

1 Basic level usage Making bank transfers

2 Moderate level usage Making payments like utility bills, credit cards

3 High level usage App linked to insurance plans

4 Advanced level usage Mortgages, stocks, other investment solutions

Categorical regression (Meulman 2003) quantifies categorical data by assigning numerical values to the categories, resulting in an optimal regression equation for the transformed variables. Categorical variables serve to separate groups of cases, and the technique estimates separate sets of parameters for each group. CATREG is a technique where nonlinearity is based on independent variables modification from numeric to categorical. The model permits a set of modifications to rank them to a dependent variable category. The CATREG command in SPSS extends the standard approach by simultaneously scaling nominal, ordinal and numerical variables in both the dependent and the independent categories. So, we would use the general functional form as

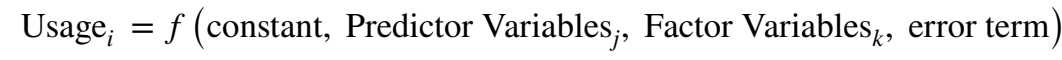

where ' $i$ ' $=1,2,3,4$ according to the level of usage specified above. ' $j$ ' $=$ demographic characteristics like age, gender, income. ' $k$ ' $=$ factors that would be identified by the principal component analysis.

The CATREG model fits the classical linear regression model with nonlinear transformations of the variables, written as

$\alpha_{\mathrm{r}}(y)=\sum_{j=1}^{J} \beta_{j} \alpha_{j}\left(x_{j}\right)+e$

The CATREG algorithm minimizes the least squares loss function derived from the above equation, where $j$ is the number of predictor variables, $\beta_{j}$ are the regression coefficients, $\alpha_{\mathrm{r}}(y)$ is the transformation for the response variable $y, \alpha_{j}\left(x_{j}\right)$ is the transformations for predictor variables $x_{j}$, and $\mathrm{e}$ is the error vector.

With the numerical scaling level, a variable is treated as quantitative, and a linear transformation is applied. With the non-numerical scaling levels, the variables are treated as qualitative, and the optimal scaling process turns them into quantitative variables. The ordinal scaling level retains the grouping and ordering information and result in a monotonic transformation in the form of a step function. The categorical regression with optimal scaling technique has been used widely in the literature for consumer studies in various sectors (Černá and Poulová 2012; Hussain et al. 2006; Nabareseh and Osakwe 2014; Xu, Capretz and Ho 2010).

\section{Results}

\section{Descriptive statistics}

The sample in the research study involved a selection of individuals representing the general demographic characteristics of the UAE. However, not everyone qualified as a respondent based on demographic requirements as the research was based on the usage of mobile banking application which required usage and awareness of basic smart phone applications. A purposive non-random sampling method was used to select respondents who were contacted through email. The questionnaire was distributed to a convenient target sample of 400 individuals in the UAE who comprised individuals who were potential users of the mobile banking applications. Out of the 400 surveyed sample, completed responses were received from 280 individuals, within which 65 responses were rejected due to incomplete feedback, missing data and mistakes in recording. Finally, 215 responses were taken as our valid sample set.

Table 1 shows the demographic characteristics of the sample, which formed the first part of the questionnaire. 
Table 1 Demographic characteristics

\begin{tabular}{|c|c|c|c|}
\hline Variable & & Frequency & Percentage \\
\hline Mobile banking & Yes & 145 & 67.4 \\
\hline & No & 70 & 32.6 \\
\hline Gender & Male & 75 & 52.1 \\
\hline & Female & 70 & 47.9 \\
\hline Age & 20-30 years & 32 & 22.3 \\
\hline & $30-40$ years & 61 & 41.7 \\
\hline & $40-50$ years & 44 & 30.2 \\
\hline & $50-60$ years & 8 & 5.8 \\
\hline Monthly Income & Below AED 10,000 & 3 & 2.1 \\
\hline & AED $10,001-15,000$ & 39 & 27.0 \\
\hline & AED 15,001-20,000 & 58 & 40.3 \\
\hline & AED 20,001-25,000 & 25 & 17.4 \\
\hline & Above AED 25,001 & 19 & 13.2 \\
\hline Smart Phone Usage & Less than 1 year & 2 & 1.4 \\
\hline & $1-3$ years & 128 & 88.3 \\
\hline & 4-6 years & 12 & 8.3 \\
\hline & $7-9$ years & 2 & 1.3 \\
\hline & More than 10 years & 1 & 0.7 \\
\hline Mobile Banking & Less than 1 month & 2 & 1.4 \\
\hline Usage & $1-6$ months & 22 & 15.2 \\
\hline & $6-12$ months & 48 & 33.1 \\
\hline & $1-2$ years & 67 & 46.2 \\
\hline & More than 2 years & 6 & 4.1 \\
\hline
\end{tabular}

Table 2 Awareness about mobile banking

\begin{tabular}{lcc}
\hline $\begin{array}{l}\text { Heard about Mobile Banking } \\
\text { from }\end{array}$ & Count & Percentage \\
\hline Bank & 87 & 60.4 \\
Friends & 48 & 33.3 \\
Internet & 1 & 0.7 \\
Advertisements & 8 & 5.6 \\
\hline
\end{tabular}

Of the 215 valid responses, 32.6 percent were not using Mobile Banking and therefore did not form a part of the sample for further analysis. Among the 145 respondents who were using their Mobile Banking app, 52.1 percent were males, and 48 percent were females, with ages ranging from a minimum of 23 years to a maximum of 55 years, with a mean of 36.3 years. The 30-40 years age-group was predominant, accounting for 41.7 percent and the largest group had a monthly income of AED 15,001-20,000. The main source of information about mobile banking apps was their bank (60.4 percent) and another 33.3 percent started using the apps after hearing from their friends (Table 2).

The 70 non-users were probed further, and the prime reason cited by 54.3 percent of the non-users for not adopting the mobile banking app was that they were unaware of the benefits of using the new technology but intended to use the app in future (Table 3). The next most important reason for non-users (27.1 percent) was that they tried using the app but were not able to understand. Another 14.3 percent of the non-users responded that they did not receive adequate information from their banks regarding the usage of their mobile banking app. These results provide important indications and insights for customer service and marketing initiatives of the banks.

Majority of respondents ( 88.3 percent) were using smartphones for 1-3 years, and 46.2 percent were using mobile banking for 1-2 years, and this has been emphasized in the cross-tabulation in Table 4. The predominant bank mobile app was from EmiratesNBD, followed by Abu Dhabi Islamic Bank and Abu Dhabi Commercial Bank (Table 5). Interestingly, in an earlier study, Abu Dhabi Islamic Bank also emerged as the most profitable bank in the UAE during the post-crisis period 2009-2015 (Banerjee and Majumdar 2018).

\section{Factor analysis}

The second part of the questionnaire comprised the factors that were assumed to affect the usage and adoption of mobile banking app. In Table 6, the value for Kaiser-Meyer-Olkin (KMO) measure of sampling adequacy (0.774) justified the applicability of factor analysis on the sample since our dataset is within the acceptable range of 0.6 to 1 , as has been elaborated earlier. Further, Bartlett's test of sphericity confirmed that the observed correlation matrix is significantly different (at 99\% level of significance) from the identity matrix, and the factors extracted would be meaningful, as per the analysis in Sect. 3. Results of confirmatory factor
Table 3 Reasons for not using mobile banking

\begin{tabular}{lcc}
\hline & Respondents & Percentage \\
\hline I am unaware of the benefits of Mobile Banking & 38 & 54.3 \\
I tried but did not understand & 19 & 27.1 \\
There was no marketing initiatives from my bank regarding & 10 & 14.3 \\
$\quad$ their Mobile Banking app & 3 & 4.3 \\
I did not see anyone else using it & 70 & 100.0 \\
TOTAL & & \\
\hline
\end{tabular}


Table 4 Cross-tabulation usage of smart phone versus mobile banking

\begin{tabular}{|c|c|c|c|c|c|c|}
\hline \multirow[b]{2}{*}{ Usage of mobile banking } & \multicolumn{5}{|c|}{ Usage of smart phones } & \multirow[b]{2}{*}{ TOTAL } \\
\hline & Less than 1 year & 1 to 3 years & 4 to 6 years & 7 to 9 years & $>10$ years & \\
\hline Less than 1 month & - & $1.40 \%$ & - & - & - & $1.4 \%$ \\
\hline 1 to 6 months & $0.70 \%$ & $13.29 \%$ & $1.40 \%$ & - & - & $15.38 \%$ \\
\hline 6 to 12 months & $0.70 \%$ & $30.77 \%$ & $1.40 \%$ & - & - & $32.86 \%$ \\
\hline 1 to 2 years & - & $41.26 \%$ & $3.30 \%$ & $0.70 \%$ & $0.70 \%$ & $45.96 \%$ \\
\hline$>2$ years & - & $1.40 \%$ & $2.33 \%$ & $0.70 \%$ & - & $4.42 \%$ \\
\hline TOTAL & $1.40 \%$ & $88.11 \%$ & $8.42 \%$ & $1.40 \%$ & $0.70 \%$ & $100.0 \%$ \\
\hline
\end{tabular}

Table 5 Banking preference

\begin{tabular}{ll}
\hline Mobile Banking linked to... & Frequency \\
\hline Emirates NBD & 61 \\
Abu Dhabi Islamic Bank & 28 \\
Abu Dhabi Commercial Bank & 26 \\
Mashreq & 22 \\
RakBank & 19 \\
Dubai Islamic Bank & 13 \\
First Gulf Bank & 10 \\
HSBC & 8 \\
National Bank of Abu Dhabi & 7 \\
Standard Chartered & 7 \\
Citibank & 4 \\
Commercial Bank International & 4 \\
Noor Bank & 3 \\
Emirates Islamic Bank & 2 \\
National Bank of Dubai & 1 \\
\hline
\end{tabular}

Table $6 \mathrm{KMO}$ and Bartlett's test

Kaiser-Meyer-Olkin measure of sampling adequacy Bartlett's test of sphericity

\begin{tabular}{lc} 
Approx. & 1430.053 \\
Chi- & \\
square & \\
df & 91 \\
Sig & .000 \\
\hline
\end{tabular}

analysis in Table 7 present values of initial eigenvalues and the rotated sums of factor loadings showing the variances, and cumulative variances explained by each construct. Results indicated that a priori assumptions were substantiated with a four-factor solution, in terms of the eigenvalues being larger than 1, which explained $77 \%$ of the variance in the data.

Table 8 shows the results of the factor analysis that was conducted using principal axis factoring with varimax rotation as an extraction method (Aczel 1999; Hair et al. 1998). It can be identified that the 14 data components from the original questionnaire were reduced in dimension into four uncorrelated independent variables through the rotated component matrix. The reliability test for the four factors was then undertaken and calculated using Cronbach's Alpha. Table 8 reveals that all the factors had a satisfactory value of Cronbach's alpha, which has been explained in Sect. 3 earlier. A reliability check on all the 14 items of the scale taken together also had an acceptable Cronbach's alpha value of 0.824 .

The first factor identified by the rotated component matrix consisted of five variables, which would correspond to the Perceived Ease and Usefulness (PEU) - this was the most important factor that influenced the usage of mobile banking app in the UAE and explained 27 percent of the total variance in usage with a Cronbach reliability score of 0.915. Perceived Ease of Use and Perceived Usefulness have been the fundamental elements of all previous technology acceptance models which conform to our hypothesis that if a consumer believes that the technology will be easy to learn and beneficial for the job, he/she is more likely to use it (Hypothesis 1). Our results also indicate that the respondents accorded the highest rating for the apps being quicker and more efficient than traditional face-to-face banking.

The second factor identified by the factor analysis showed a high correlation of four variables that related to the security and privacy (SP) of banking transactions and explained another 23 percent of the total variance in the data (Hypothesis 2), with safety and confidentiality being given the highest importance in this study.

The third factor was the amount of Information (INFO) that the customers received about the benefits and relevance of mobile banking (Hypothesis 3). The last factor included two variables referring to speed and reliability of the Internet Connectivity (IC) where the importance of a trustworthy, reliable network in mobile banking was highlighted by the respondents (Hypothesis 4).

\section{Regression analysis}

The categorical regression equation can be specified as follows: 
Table 7 Total variance explained

\begin{tabular}{|c|c|c|c|c|c|c|}
\hline \multirow[t]{2}{*}{ Component } & \multicolumn{3}{|c|}{ Initial eigenvalues } & \multicolumn{3}{|c|}{ Rotation sums of squared loadings } \\
\hline & Total & $\%$ of Variance & Cumulative \% & Total & $\%$ of Variance & Cumulative $\%$ \\
\hline 1 & 5.359 & 38.276 & 38.276 & 3.758 & 26.843 & 26.843 \\
\hline 2 & 2.356 & 16.826 & 55.102 & 3.256 & 23.255 & 50.098 \\
\hline 3 & 1.622 & 11.589 & 66.691 & 2.101 & 15.009 & 65.106 \\
\hline 4 & 1.465 & 10.464 & 77.155 & 1.687 & 12.048 & 77.155 \\
\hline 5 & .662 & 4.728 & 81.883 & & & \\
\hline 6 & .599 & 4.277 & 86.160 & & & \\
\hline 7 & .442 & 3.158 & 89.318 & & & \\
\hline 8 & .393 & 2.804 & 92.122 & & & \\
\hline 9 & .322 & 2.297 & 94.419 & & & \\
\hline 10 & .311 & 2.219 & 96.638 & & & \\
\hline 11 & .171 & 1.225 & 97.862 & & & \\
\hline 12 & .153 & 1.094 & 98.957 & & & \\
\hline 13 & .103 & .734 & 99.690 & & & \\
\hline 14 & .043 & .310 & 100.000 & & & \\
\hline
\end{tabular}

Extraction method: Principal component analysis

\begin{tabular}{lllrrr}
\hline Component & \multicolumn{1}{l}{ l } & \multicolumn{1}{l}{ l } & \multicolumn{1}{l}{ Cronbach Alpha } \\
\hline App makes banking quick & .887 & .047 & .210 & -.010 & \multicolumn{1}{l}{0.915} \\
App makes banking efficient & .869 & .042 & .232 & .001 & \\
App is user-friendly & .850 & .275 & .067 & .062 & \\
App is user-friendly easy to learn & .793 & .273 & -.005 & .197 & \\
App is easy to navigate & .765 & .250 & .071 & .113 & \\
It is safe to use the mobile app & .178 & .922 & .038 & .045 & 0.919 \\
My mobile transactions are confidential & .099 & .897 & .037 & -.009 & \\
I have trust that privacy would be maintained & .172 & .883 & .043 & .105 & \\
My mobile transactions are legally secure & .351 & .761 & -.011 & .273 & \\
Receive information of Benefits of Mobile App & .070 & .041 & .878 & -.041 & 0.774 \\
Information is relevant to my needs & .138 & .003 & .827 & -.101 & \\
Bank provides adequate information & .198 & .050 & .728 & .297 & \\
Reliable internet connectivity & .020 & .090 & -.010 & .885 & 0.702 \\
Fast internet connectivity & .148 & .114 & .058 & .812 & \\
\hline
\end{tabular}

Extraction method: Principal component analysis

Rotation method: Varimax with kaiser normalization
Table 8 Rotated component matrix (Rotation converged in 5 iterations)

Usage $_{i}=f($ constant, PEU, SP, INFO, IC, gender, age, mBank, error term)

where the dependent variable was a categorical ordinal variable for the level of usage of the mobile banking app. The factor scores from the Principal Component Analysis were taken for the independent variables, namely perceived ease and usefulness (PEU); Security and Privacy (SP); Amount of Information (INFO) and Internet Connectivity (IC). Three moderating variables have been included in the regression, namely, gender, age and years of mobile banking usage (mBank).
The dependent variable (Usage) ranged from basic level usage to advanced level of banking services. Bank transfers were categorized as the basic banking service and using the mobile app for making payments like utility bills, credit cards, road tolls, school fees, etc., was termed as moderate level usage. Customers who had linked their mobile apps to their insurance plans and making their premium payments through the app were termed as high level users. Finally, those who had their investment plans, stock 
market accounts, mortgage payments on their apps were categorized as advanced level users of mobile banking.

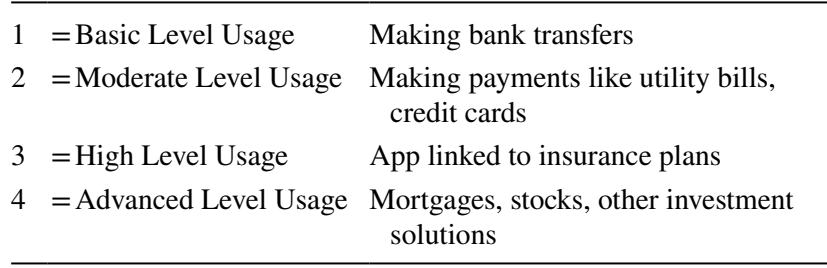

According to their level of usage, the respondents were assigned numerical categories that corresponded to a linear ordinal scale such that a response of ' 2 ' is higher than a response of ' 1 ', but the difference is not necessarily the same as the difference between ' 3 ' and ' 2 '. This was used as an ordinal categorical dependent variable for the regression analysis.

Results of the regression analysis presented in Table 9 reveal that factor 1 (PEU) and factor 3 (INFO) were the most influential factors explaining the usage of mobile banking apps in the UAE, at $99 \%$ level of significance. This result confirms our hypotheses 1 and 3 that consumers use mobile banking applications for the benefits it provides in comparison to other banking delivery channels, and the level of adoption (ranging from basic account checks to high level stock market activities) depends on how well-informed the consumers are regarding the features, benefits and procedures of the apps. The level of usage of the banking application depends on the extent to which the m-banking is free of effort (Davis 1989; Venkatesh and Davis 2000), which also confirms that the use of new technology needs to be without mental stress and easy to use (Rauniar et al. 2014). Those who perceive mobile banking as user-friendly and effortless would be the ones to utilize the applications and upgrade their usage from a basic level to the advanced.

Awareness and access to information had a significant positive impact on the adoption of mobile banking. Our result is consistent with the findings of Laukkannen and Kiviniemi (2010), Huang et al. (2011), Hanafizadeh and Khedmatgozar (2012) and Al-Somali et al. (2010). Awareness is considered essential in enhancing the customer's readiness toward the adoption and usage of technology. More importantly, our results revealed that the deficiency of information was the prime reason for strong inhibition toward the adoption, as was found by Qazi et al., 2016. Banks need to increase consumer awareness by disseminating relevant information through mass media or social networking sites, especially regarding features such as m-shopping, $\mathrm{m}$-ticketing.

Speed and reliability of internet connectivity (Hypotheses 4) showed a negative weak significance at $90 \%$ level, which is in contrast with the expected result. The negative sign depicts that although UAE has impressive high-speed internet connectivity, this has not resulted in users graduating from basic to advanced banking transactions through their mobile apps. Based on our earlier analysis, the negative sign

Table 9 Regression for categorical data (CATREG)

\begin{tabular}{|c|c|c|c|c|c|}
\hline \multicolumn{6}{|c|}{ Model summary } \\
\hline Multiple R & R Square & \multicolumn{2}{|c|}{ Adjusted R Square } & \multicolumn{2}{|c|}{ Apparent Prediction Error } \\
\hline .754 & .569 & \multicolumn{2}{|c|}{.536} & \multicolumn{2}{|c|}{.233} \\
\hline ANOVA & Sum of Squares & df & Mean Square & $\mathrm{F}$ & Sig \\
\hline Regression & 52.044 & 7 & 7.435 & 11.116 & .000 \\
\hline Residual & 88.956 & 133 & .669 & & \\
\hline Total & 141.000 & 140 & & & \\
\hline \multirow[t]{2}{*}{ Coefficients } & \multicolumn{2}{|c|}{ Standardized Coefficients } & df & $\mathrm{F}$ & Sig \\
\hline & Beta & \multicolumn{2}{|c|}{$\begin{array}{l}\text { Bootstrap (1000) Estimate of Std. } \\
\text { Error }\end{array}$} & & \\
\hline Age & .096 & .070 & 1 & 1.883 & .172 \\
\hline mBank & .162 & .110 & 1 & 2.196 & .141 \\
\hline Gender & .054 & .057 & 1 & .924 & .338 \\
\hline FAC1 (PEU) & .457 & .090 & 1 & 25.571 & $.000 * * *$ \\
\hline FAC2 (SP) & -.122 & .102 & 1 & 1.439 & .232 \\
\hline FAC3 (INFO) & .328 & .067 & 1 & 24.164 & $.000 * * *$ \\
\hline FAC4 (IC) & -.189 & .060 & 1 & 9.980 & $.002 * *$ \\
\hline
\end{tabular}

Dependent variable: Usage

*** and * represent significance at $99 \%$ and $90 \%$ levels, respectively. 
of the coefficient would be ascribed to the lack of awareness and absence of adequate information about the various $\mathrm{m}$-banking services available to them. The weak significance is also in contrast with the studies in other parts of the globe where internet speed is a significant frustration. Users face buffering time and hang time while undertaking any online banking transaction and therefore showed the high significance of regression coefficients for studies in many other countries. Download speed and transaction speed emerged as major impediments in countries like Turkey (Sayar and Wolfe 2007), Bangladesh (Islam et al. 2018) and India (Sihare 2017) among others. However, high-speed and reliability are commonplace in the UAE and do not hold much importance since the government has ensured the fastest internet connectivity in the country, as in the case of Singapore (Sheshadri and Rani 2014).

The moderating variables (age, gender and duration of mobile banking) were statistically insignificant, indicating that the socio-demographic factors did not influence the adoption of mobile banking applications among the respondents in the UAE. This result is in contrast with the existing studies based on respondents from Asia and Europe where gender emerged as a significant predictor of acceptance and usage of mobile banking (Riquelme and Rios 2010; Venkatesh and Morris 2000), Gefen and Straub 2000). Others also found age is a significant explanatory variables as elderly people were found to have less interest on technological innovations (Howcroft et al. 2002; Mattila et al. 2003; Yang 2005; Porter and Donthu 2006). Interestingly, Akman and Mishra (2010) found that duration did not have any impact on the level of usage, which included electronic services like e-communication, e-shopping, e-banking and e-government and was in support of our result.

\section{Results and conclusions}

Banking services through mobile devices is an emerging service by commercial banks in developing country like the UAE. Our study investigates the factors that influence adoption and usage of mobile banking through exploratory factor analysis. A categorical regression analysis has been undertaken to ascertain the impact of these factors on the level of usage of the mobile app by customers. The initial Principal Component Analysis identified four factors-namely perceived ease and usefulness, information, security and privacy and connectivity - that might have an impact on the acceptance of online banking.

In our sample, 32.6 percent of the respondents were nonusers of mobile banking apps. The non-users revealed that the prime reason for not adopting mobile transactions was the lack of awareness of the benefits of using the new technology since they did not receive adequate information from their banks. The result provides insights for customer service and marketing initiatives that banks need to adopt. The regression analysis indicated that socio-demographic factors, like age and gender, did not influence the adoption of mobile banking applications among the respondents in the UAE. Importantly, perceived ease and usefulness (Hypothesis 1) and information (Hypothesis 3 ) were the most influential factors explaining the usage and adoption of mobile banking apps.

The study contributes to electronic banking literature by providing insights into the factors that affect online banking acceptance in the UAE. Our results offer critical marketing strategies for banking professionals, whereby software developers and marketing experts should pay attention to convince consumers about the benefits and ease of using the apps. Adoption of mobile apps depends on the new technology being perceived as easy to use, effortless, convenient and user-friendly. Marketing initiatives of the banks have to be geared toward raising awareness of the apps that would enhance the adoption and usage of the technology. In fact, Karjaluoto et al. (2019) highlighted that banks' investments in developing mobile apps in Finland resulted in improved relationships with customers and increased business. Along with introducing new technology, the relevant information has to reach consumers to increase awareness to move from basic to advanced usage of the apps. Banks need to provide continuous communication, updates, guidance and demonstrations for their clients, especially for the current non-users of the technology.

\section{Limitations and scope of further research}

This study reflects the perceptions of users of the mobile banking app in the UAE, and further research could be carried out to check the robustness of the conclusions by extending the dataset to the GCC region and other similar emerging markets. The focus of the research could also be extended to include factors that might prompt post-adoption usage, in terms of future intentions of users to adopt advanced application levels. Further, it would add value to investigate future adoption intentions of the non-users as well.

The present study sought to explore the level of usage of mobile banking applications among the active users, which justified the use of the categorical regression model. However, a multivariate technique could be used to focus on the factors affecting the adoption of mobile banking through structural equation modeling (SEM). SEM has been used extensively in the existing literature, along with confirmatory factor analysis and path analysis, to test causal relationships between variables. 
Fig. 1 The model

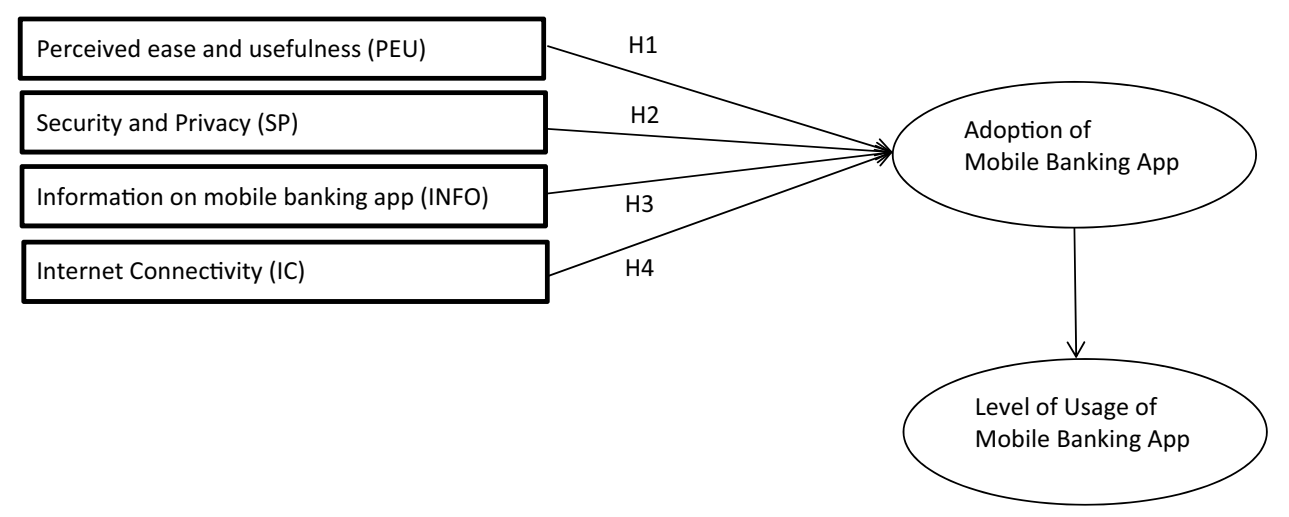

One could also conclude that COVID-19 would increase the usage of mobile banking due to two factors. Firstly, mobile banking would promote the social distancing policy and other COVID-19 protocols, enabling people to make transactions safely and securely from their homes. Secondly, COVID-19 has increased the usage of smartphones around the world and is likely to have its positive linkage for mobile banking. Fintech companies that have digitally transformed themselves during the pandemic with mobile banking applications, smart payment options and e-commerce, are expected to benefit from this behavioral shift. Therefore, it would be an important extension of our study to investigate the levels of usage after the present pandemic (Fig 1).

\section{References}

Aboelmaged, M., and T.R. Gebba. 2013. Mobile banking adoption: An examination of technology acceptance model and theory of planned behavior. International Journal of Business Research and Development 2 (1): 35-50.

Aczel, A.D. 1999. Sampling methods. Complete business statistics. , Boston: Irwin/McGraw-Hill.

Ajzen, I. 1991. The theory of planned behavior. Organizational Behavior and Human Decision Process 50 (2): 179-211.

Ajzen, I., and M. Fishbein. 1980. Understanding attitudes and predicting social behavior. Englewood Cliffs, NJ: Prentice-Hall.

Akman, I., and A. Mishra. (2010). Gender, age and income differences in internet usage among employees in organizations. Computers in Human Behavior 26 (3): 482-490.

Al-Gahtani, S. 2001. The applicability of TAM outside North America: An empirical test in the United Kingdom. Information Resources Management Journal 14 (3): 37-46.

Al-Somali, S.A., R. Gholami, and B. Clegg. 2009. An investigation into the acceptance of online banking in Saudi Arabia. Technovation 29 (2): 130-141.

Amin, H., M.R.A. Hamid, S. Lada, and Z. Anis. 2008. The adoption of mobile banking in Malaysia: The case of Bank Islam Malaysia Berhad (BIMB). International Journal of Business and Society 9 (2): 43-53.

Banerjee, R., and S. Majumdar. 2018. Does financial regulation influence bank efficiency? A study on UAE banking sector. In Advances in panel data analysis in applied economic research, ed. N. Tsounis and A. Vlachvei. New York: Springer.
Black, N.J., A. Lockett, C. Ennew, H. Winklhofer, and S. McKechnie. 2002. Modelling consumer choice of distribution channels: An illustration from financial services. International Journal of Bank Marketing 20 (4): 161-173.

Černá, M., and P. Poulová. 2012. Social software applications and their role in the process of education from the perspective of university students. The Proceedings of the 11th European Conference on $e$-Learning. The Netherlands: University of Groningen.

Cerny, C.A., and H.F. Kaiser. 1977. A study of a measure of sampling adequacy for factor-analytic correlation matrices. Multivariate Behavioral Research 12 (1): 43-47.

Chen, I.-C., and R. Ching. 2002. A proposed framework for transitioning to an e-business model. Quarterly Journal of Electronic Commerce 3 (4): 375-389.

Churchill, G.A. 1995. Marketing research: Methodological foundation, 6th ed. Sydney: Dryden Press.

Cranor L.F., J. Reagle, and M.S. Ackerman. 1999. Beyond concern: Understanding net users' attitudes about online privacy. The Internet Upheaval: Raising Questions, Seeking Answers in Communications Policy 47-70.

Cronbach, L.J. 1951. Coefficient alpha and the internal structure of tests. Psychometrika 16 (3): 297-334.

Cruz, P., L.B.F. Neto, P. Munoz-Gallego, and T. Laukkanen. 2010. Mobile banking rollout in emerging markets: Evidence from Brazil. International Journal of Bank Marketing 28 (5): 342-371.

Curran, J.M., and M.L. Meuter. 2005. Self-service technology adoption: Comparing three technologies. Journal of Services Marketing 19 (2): 103-113.

Dasgupta, S., R. Paul, and S. Fuloria. 2011. Factors affecting behavioral intentions towards mobile banking usage: Empirical evidence from India. Romanian Journal of Marketing 3 (1): 6-28.

Davis, F.D. 1989. Perceived usefulness, perceived ease of use, and user acceptance of information technology. MIS Quarterly 13 (3): 319-339.

Davis, F.D., R.P. Bagozzi, and P.R. Warshaw. 1989. User acceptance of computer technology: A comparison of two theoretical models. Management Science 35 (8): 982-1003.

Ensor, B., T. Montez, and P. Wannemacher. 2012. The state of mobile banking. USA: Forrester Research.

Fishbein, M.A., and I. Ajzen. 1975. Belief, attitude, intention and behavior: An introduction to theory and research. MA: AddisonWesley Reading.

Fisher, R.A. 1922. On the mathematical foundations of theoretical statistics. Philosophical Transactions of the Royal Society of London 222: 309-368.

Gefen, D., and D.W. Straub. 2000. The relative importance of perceived ease of use in IS adoption: A study of e-commerce adoption. Journal of the Association for Information Systems 1 (1): 1-28. 
Giglio, V. 2002. Privacy in the world of cyberbanking: Emerging legal issues and how you are protected. The Secured Lender 58 (2): $48-60$.

Glavee-Geo, R., A.A. Shaikh, and H. Karjaluoto. 2017. Mobile banking services adoption in Pakistan: Are there gender differences? International Journal of Bank Marketing. 35 (7): 1090-1114.

Guriting, P., and A. Ndubisi. 2006. Borneo online banking: Evaluating customer perceptions and behavioral intention. Management Research News 29 (1-2): 6-15.

Hair, J.F., R.E. Anderson, R.L. Tatham, and W.C. Black. 1998. Multivariate Data Analysis, 5th ed. Englewood Cliffs, NJ: Prentice-Hall.

Hamlet, C., and M. Strube. 2000. Community banks go online. $A B A$ Banking Journal 92 (3): 61-65.

Hanafizadeh, P., and H.R. Khedmatgozar. 2012. The mediating role of the dimensions of the perceived risk in the effect of customers' awareness on the adoption of Internet banking in Iran. Electronic Commerce Research 12 (2): 151-175.

Heijden, H., T. Verhagen, and M. Creemers. 2003. Understanding online purchase intentions: Contributions from technology and trust perspectives. European Journal of Information Systems 12 (1): 41-48.

Hoffman, D.L. and T.P. Novak. 1998. Trustbuilders vs trustbusters. The Industry Standard.

Howcroft, B., R. Hamilton, and P. Hewer. 2002. Consumer attitude and the usage and adoption of home-based banking in the United Kingdom. International Journal of Bank Marketing 20 (3): 111-121.

Huang, D.L., P.L.P. Rau, G. Salvendy, F. Gao, and J. Zhou. 2011. Factors affecting perception of information security and their impacts on IT adoption and security practices. International Journal of Human-Computer Studies 69 (12): 870-883.

Hussain, M., R. Castaldi, and S. Cholette. 2006. Determinants of wine consumption of U.S. consumers: An econometric analysis. $3 r d$ International Wine Business Research Conference. Montpellier.

Islam, N., M. Mustafi, M. Rahman, N. Nower, M. Rafi, M. Asef, M.T. Natasha, R. Hassan, and S. Afrin. 2018. Factors affecting customers' experience in mobile banking of Bangladesh. Global Journal of Management and Business Research 19 (5): 37-49.

Kaiser, H.F. 1970. A second generation little jiffy. Psychometrika 35: 401-415.

Karjaluoto, H., A.A. Shaikh, H. Saarijärvi, and S. Saraniemi. 2019a. How perceived value drives the use of mobile financial services apps. International Journal of Information Management 47: 252-261.

Karjaluoto, H., A.A. Shaikh, M. Leppäniemi, and R. Luomala. 2019b. Examining consumers' usage intention of contactless payment systems. International Journal of Bank Marketing 38 (2): 332-351.

Karjaluoto, H., T. Koivumaki, and J. Salo. 2003. Individual differences in private banking: Empirical evidence from Finland. In: Proceedings of the 36th annual hawaii international conference on system sciences, 1-9.

Ketkar, S.P., R. Shankar, and D.K. Banwet. 2012. Structural modeling and mapping of m-banking influences in India. Journal of Electronic Commerce Research 13 (1): 70-87.

Khalifa, M., and K. Shen. 2008. Explaining the adoption of transactional B2C mobile commerce. Journal of Enterprise Information Management 21 (2): 110-124.

Khalilzadeh, J., A.B. Ozturk, and A. Bilgihan. 2017. Security-related factors in extended UTAUT model for NFC based mobile payment in the restaurant industry. Computers in Human Behavior 70: 460-474.

Kleijnen, M., M. Wetzels, and K.D. Ruyter. 2004. Consumer acceptance of wireless finance. Journal of Financial Services Marketing 8 (3): 206-217.
Koenig-Lewis, N., A. Palmer, and A. Moll. 2010. Predicting young consumers' take up of mobile banking services. International Journal of Bank Marketing 28 (5): 410-432.

Laforet, S., and X. Li. 2005. Consumers' attitudes towards online and mobile banking in China. International Journal of Bank Marketing 23 (5): 362-380.

Lai, J., and C. Yang. 2009. Effects of employees' perceived dependability on success of enterprise applications in e-business. Industrial Marketing Management 38: 263-274.

Laukkanen, T. 2007. Internet vs mobile banking: Comparing customer value perceptions. Business Process Management Journal 13 (6): 788-797.

Laukkanen, T., and V. Kiviniemi. 2010. The role of information in mobile banking resistance. International Journal of Bank Marketing 28 (5): 372-388.

Lee, M.S., P.J. McGoldrick, K.A. Keeling, and J. Doherty. 2003. Using ZMET to explore barriers to the adoption of $3 \mathrm{G}$ mobile banking services. International Journal of Retail and Distribution Management 31 (6): 340-348.

Liao, C., J.-L. Chen, and D. Yen. 2007. Theory of planning behavior (TPB) and customer satisfaction in the continued use of e-service: An integrated model. Computers in Human Behavior 23 (6): 2804-2822

Lin, J.-S., and H.-C. Chang. 2011. The role of technology readiness in self-service technology acceptance. Managing Service Quality 21 (4): 424-444.

Luarn, P., and H.H. Lin. 2005. Toward an understanding of the behavioral intention to use mobile banking. Computers in Human Behavior 21 (6): 873-891.

Mathieson, K. 1991. Predicting user intentions: Comparing the technology acceptance model with the theory of planned behavior. Information Systems Research 2 (3): 173-191.

Mattila, M., H. Karjaluoto, and T. Pento. 2003. Internet banking adoption among mature customers: Early majority or laggards? Journal of Services Marketing 17 (5): 514-528.

McCloskey, D.W. 2006. The importance of ease of use, usefulness, and trust to online consumers: An examination of the technology acceptance model with older consumers. Journal of Organizational and End User Computing 18 (3): 47-65.

McKechnie, S., H. Winklhofer, and C. Ennew. 2006. Applying the technology acceptance model to the online retailing of financial services. International Journal of Retail and Distribution Management 34 (4/5): 388-410.

Meulman, J.J. 2003. Prediction and classification in nonlinear data analysis: Something old, something new, something borrowed, something blue. Psychometrika 68 (4): 493-517.

Mols, N.P., D. Nikolaj, P. Bukh, and J. FlohrNielsen. 1999. Distribution channel strategies in Danish retail banking. International Journal of Retail and Distribution Management 27 (1): 37-47.

Moon, J.-W., and Y.-G. Kim. 2001. Extending the TAM for a world wide web context. Information and Management 38 (4): 217-230.

Morosan, C., and M. Jeong. 2008. Users' perceptions of two types of hotel reservation web sites. International Journal of Hospitality Management 27 (2): 284-292.

Nabareseh, S., and N.C. Osakwe. 2014. Can business-to-consumer electronic commerce be a game changer in anglophone west african countries? Insights from secondary data and consumers' perspectives. World Applied Sciences Journal 30 (11): 1515-1525.

Nysveen, H., P.E. Pedersen, and H. Thorbjernsen. 2005. Explaining intention to use mobile chat services: Moderating effects of gender. The Journal of Consumer Marketing 22 (4): 247-256.

Polatoglu, V.N., and S. Ekin. 2001. An empirical investigation of the Turkish consumers' acceptance of Internet banking services. International Journal of Bank Marketing 19 (4): 156-165. 
Porter, C.E., and N. Donthu. 2006. Using the technology acceptance model to explain how attitudes determine Internet usage: The role of perceived access barriers and demographics. Journal of Business Research 59 (9): 999-1007.

Pousttchi, K. and M. Schurig. 2004. Assessment of today's mobile banking applications from the view of customer requirements. In Proceedings of the 37th annual hawaii international conference on system sciences, 1-10.

Qazi, W., S.A. Raza, and N. Shah. 2018. Acceptance of e-book reading among higher education students in a developing country: The modified diffusion innovation theory. International Journal of Business Information Systems 27 (2): 222-245.

Rauniar, R., G. Rawski, J. Yang, and B. Johnson. 2014. Technology acceptance model (TAM) and social media usage: An empirical study on Facebook. Journal of Enterprise Information Management 27: 6-30.

Riquelme, H.E., and R.E. Rios. 2010. The moderating effect of gender in the adoption of mobile banking. International Journal of Bank Marketing 28 (5): 328-341.

Robinson, T. 2000. Internet banking: Still not a perfect marriage. InformationWeek 782: 104-104.

Roboff, G., and C. Charles. 1998. Privacy of financial information in cyberspace: Banks addressing what consumers want. Journal of Retail Banking Services 20 (3): 51-56.

Sathye, M. 1999. Adoption of Internet banking by Australian consumers: An empirical investigation. International Journal of Bank Marketing 17 (7): 324-334.

Sayar, C., and S. Wolfe. 2007. Internet banking market performance: Turkey versus the UK. International Journal of Bank Marketing 25 (3): 122-141.

Sheshadri, P., and S. Rani. 2014. The influence of government support in the adoption of internet banking. International Journal of Applied Business and Economic Research 12 (3): 803-811.

Sihare, S.R. 2017. Role of m-Banking for Indian rural consumers, its adaptation strategies, and challenges: Consumer behavior analysis. International Journal of Information Engineering and Electronic Business 9 (6): 35-42.

Sripalawat, J., M. Thongmak, and A. Ngramyarn. 2011. M-banking in metropolitan Bangkok and a comparison with other countries. Journal of Computer Information Systems 51 (3): 67-76.

Suoranta, M., and M. Mattila. 2004. Mobile banking and consumer behaviour: New insights into the diffusion pattern. Journal of Financial Services Marketing 8 (4): 354-366.
Tan, M., and T.S.H. Teo. 2000. Factors influencing the adoption of internet banking. Journal of the Association for Information Systems 1 (5): 1-44.

TechSci Research Report. 2018. UAE mobile wallet market 20142022. Techsci Research from Now to Next.

Teo, T.S., V.K. Lim, and R.Y. Lai. 1999. Intrinsic and extrinsic motivation in Internet usage. Omega 27 (1): 25-37.

Thusi, P., and D.K. Maduku. 2020. South African millennials' acceptance and use of retail mobile banking apps: An integrated perspective. Computers in Human Behavior 111: 106405.

Venkatesh, V., and F.D. Davis. 2000. A theoretical extension of the technology acceptance model: Four longitudinal field studies. Management Science 46 (2): 186-204.

Venkatesh, V., and M.G. Morris. 2000. Why don't men ever stop to ask for directions? gender, social influence, and their role in technology acceptance and usage behaviour. MIS Quarterly 24 (1): 115-140.

Wei, T., G. Marthandan, A. Chong, K. Ooi, and S. Arumugam. 2009. What drives Malaysian m-commerce adoption? An empirical analysis. Industrial Management and Data Systems 109 (3): 370-388.

Xu, J., L.F. Capretz, and D. Ho. 2010. Building an OSS quality estimation model with CATREG. International Journal on Computer Science and Engineering 2 (6): 1952-1958.

Yang, K.C.C. 2005. Exploring factors affecting the adoption of mobile commerce in Singapore. Telematics and Informatics 22 (3): 257-277.

Yang, A.S. 2009. Exploring adoption difficulties in mobile banking services. Canadian Journal of Administrative Sciences 26 (2): 136-149.

Zhou, T. 2011. An empirical examination of initial trust in mobile banking. Internet Research 21 (5): 527-540.

Publisher's Note Springer Nature remains neutral with regard to jurisdictional claims in published maps and institutional affiliations. 